\title{
Fundar escuelas para consolidar la República y formar ciudadanos. Una aproximación para el caso colombiano, 1819-1825
}

\author{
Found schools to consolidate the Republic and shape citizens. An \\ approach to the case of Colombia, 1819-1825
}
Fundar escolas para assegurar a República e construir cidadãos. Uma abordagem ao caso colombiano, 1819-1825

\author{
Roger Pita Pico ${ }^{2}$ \\ Academia Colombiana de Historia (Colombia)
}

Recepción: 15/09/2014

Evaluación: 28/11/2014

Aceptación: 15/05/2015

Artículo de reflexión

\section{RESUMEN}

El naciente gobierno republicano económica, el déficit fiscal y la tensión emprendió esfuerzos con miras a político-militar en medio de una frágil y brindarle mayor importancia a las fluctuante estructura administrativa. Esta escuelas primarias. Estos establecimientos fueron concebidos no solo como un nivel situación conllevó a plantear nuevas y de formación básica para el desarrollo cultural e intelectual de los ciudadanos, sino también como un espacio propicio variadas fórmulas de financiación, lo cual implicó un apoyo y un compromiso más activo por parte de la comunidad y de las instancias de gobierno a escala local.

para entronizar en la sociedad los Palabras clave: Revista Historia de la principios liberales y republicanos. Educación Latinoamericana, educación, Los ambiciosos planes en cobertura de educación primaria se tropezaron con escuelas primarias, cobertura, financiación, República, Colombia, siglo XIX. un ambiente hostil signado por la crisis

\footnotetext{
$1 \quad$ El presente artículo hace parte de un proyecto de investigación que de manera independiente adelanta el autor sobre Educación y Estado en Colombia en los primeros años de la República: los dilemas y entresijos del proceso de construcción nacional.

2 Magíster en Estudios Políticos de la Pontificia Universidad Javeriana (Bogotá). Miembro de Número en la Academia Colombiana de Historia. Director de la Biblioteca "Eduardo Santos" de la Academia Colombiana de Historia. Email: rogpitc@hotmail.com
} 


\section{ABSTRACT}

The nascent republican government undertook efforts to give greater importance to primary schools. These institutions were conceived not only as a level of basic shaping for the cultural and intellectual development of citizens, but also as an enabling space to enthrone society under liberal and republican principles. The ambitious coverage plans in primary education ran into a hostile environment marked by the economic crisis, the fiscal deficit, and the politicalmilitary tension all this amid a fragile and fluctuating administrative structure. This situation led to propose new and varied forms of financing, which involved a more active support and commitment from the community and government agencies at local scale.

Key words: Journal History of Latin American Education, education, elementary schools, coverage, financing, Republic, Colombia, XIX century.

\section{RESUMO}

O governo republicano nascente empreendeu esforços para dar maior importância às escolas primárias. As escolas foram concebidas não apenas como um nível básico de formação para o desenvolvimento cultural e intelectual dos cidadãos, mas também como um espaço para promover os princípios liberais e republicanas. Os planos ambiciosos na cobertura da educação primária enfrentou um ambiente hostil marcado pela crise econômica, o déficit fiscal ea tensão político-militar em meio a uma estrutura administrativa frágil e flutuante. Esta situação levou a representar novas e variadas formas de financiamento, o que envolveu um apoio mais activo e empenho da comunidade e agências governamentais locais.

Palavras-chave: Revista de História da Educação da América Latina, educação, escolas primárias, cobertura, financiamento, República, Colômbia, do século XIX.

\section{INTRODUCCIÓN}

En la época de dominio hispánico, a las escuelas elementales no se les prestó mucha atención en el territorio del Nuevo Reino de Granada. Algunas eran anexas a los colegios pero la gran mayoría eran fundadas por conventos que ofrecían ese servicio educativo de manera gratuita. Existían algunos planteles privados, especialmente en la provincia de Antioquia ${ }^{3}$.

En respuesta a estos vacíos, el naciente gobierno republicano que se formó en Colombia ${ }^{4}$ a partir de la batalla de Boyacá del 7 de agosto de 1819 enfocó

3 Evelyn Ahern, "El desarrollo de la educación en Colombia: 1820-1850", en Revista Colombiana de Educación. No. 22-23 (1991): 17-21. Sobre el desarrollo de la escuela en tiempos coloniales, véase: Roger Pita Pico, "Las escuelas coloniales durante la visita de Moreno y Escandón al nororiente neogranadino: el camino hacia la secularización y el equipamiento urbano", en Revista Historia de la Educación Colombiana. No. 14 (2011), 31-49; Bárbara Yadira García Sánchez, "La educación colombiana en la Nueva Granada: entre lo doméstico y lo público", en Revista Historia de la Educación Latinoamericana. No. 7 (2005): 217-238.

4 El artículo se refiere exclusivamente al territorio de lo que corresponde a la actual República de Colombia aunque cabe precisar que, para la época objeto de este estudio, hacía parte del proyecto político bolivariano denominado la Gran Colombia en donde también estaban incluidos los territorios de Venezuela y Ecuador. 
buena parte de sus esfuerzos en materia educativa en las escuelas primarias. Sin embargo, el contexto económico no era muy favorable pues se experimentaba una aguda crisis económica como consecuencia de las guerras de Independencia. El proceso de recuperación era lento y apenas se realizaban ajustes al andamiaje político-administrativo.

Este artículo tiene por objeto analizar, para el período comprendido entre 1819 y 1825, cómo el gobierno republicano afrontó los retos de cobertura y financiación de las escuelas públicas de primeras letras para niños en medio de un ambiente social, económico y político adverso. Esto remite también a reflexionar en cómo se desarrollaron estos propósitos en una etapa de transición en la cual era evidente el choque de mentalidades entre los valores del antiguo régimen español y los principios liberales.

De igual manera se intenta estudiar cómo se dio el juego de fuerzas entre un Estado que aspiraba a mantener el control y vigilancia en materia de educación y, por otro lado, la actitud de la Iglesia que por siglos había ejercido una gran influencia no solo en materia de instrucción académica sino en la formación moral de la sociedad. De algún modo, este conflicto de intereses marcó el ritmo con el cual el gobierno republicano pudo finalmente aplicar sus reformas.

El tema de la financiación fue sin lugar a dudas, uno de los más complejos, pero asimismo, abrió el camino a un interesante abanico de fórmulas innovadoras y de esfuerzos mancomunados entre instancias públicas, privadas y comunitarias que, en últimas, le imprimió un especial impulso al proyecto educativo como modelo de compromiso colectivo.

Otro de los problemas claves de investigación planteados en este artículo, hace alusión al papel que cumplieron las escuelas públicas dentro del propósito de consolidación del proyecto republicano y de los principios inherentes a esta apuesta política. En cierta medida, a través del proyecto educativo el gobierno, bajo el especial liderazgo del vicepresidente Francisco de Paula Santander, buscó entronizar estratégicamente los valores liberales y fortalecer la legitimidad de un sistema político que intentaba consolidarse como una verdadera alternativa en contraposición al antiguo régimen implantado en estas tierras por más de tres siglos. Precisamente, las ceremonias de apertura de escuelas y los certámenes académicos fueron los espacios privilegiados para difundir las ventajas de una República libre y soberana.

Este trabajo de investigación se realizó con base en fuentes primarias de archivo, informes oficiales, leyes y decretos y, de manera especial, la prensa que por estos años experimentaba un singular auge, en cuyas páginas se informaba no solamente sobre las decisiones oficiales sino que además se constituyó en un espacio a través del cual se registraron intensos debates, particularmente en relación con el tema de la financiación de las escuelas. 
“El 6 de octubre de 1820, el vicepresidente Francisco de Paula Santander, dictó un decreto que es considerado el primer plan de educación primaria. Allí, se reconoció que la instrucción pública era el medio más fácil para que los ciudadanos asimilaran sus derechos y deberes en sociedad, siendo responsabilidad del Estado asegurarles la educación para contribuir a su bienestar y felicidad. Adicionalmente, Santander hizo referencia a una justificación de carácter político al traer a colación la medida tomada por el Congreso de Angostura, que habilitó a partir del año 1830 el derecho al voto únicamente a aquellas personas que supieran leer y escribir. En tal sentido, la educación elemental se constituía en un requisito esencial para hacer valer los derechos ciudadanos en el marco de un gobierno representativo.

Los maestros debían enseñar a los niños a leer, escribir y contar, y además explicar los dogmas de la religión y de la moral cristiana. Como todavía en 1820 la República libraba estrategias para defender los territorios emancipados y para expulsar a los españoles de la Costa Caribe y de las provincias de Popayán y Pasto, se ordenó que los niños debían recibir enseñanza militar los jueves en la tarde y los días de fiesta" ${ }^{5}$, para lo cual "[...] tendrán fusiles de palo y se les arreglará por compañías, nombrándose por el maestro los sargentos y cabos entre aquellos que tuvieren más edad y más disposición. El maestro será el comandante" ${ }^{\prime 6}$.

Con este decreto, el gobierno abrigaba la esperanza de que las ciencias, las artes, la agricultura y la industria progresaran a medida que el hábito de la lectura, la escritura y la aritmética se hicieran más comunes ${ }^{7}$. Este precedente normativo abrió el camino para nuevos impulsos a escala regional. El 28 de febrero de 1821, el gobierno de Antioquia expidió un reglamento para la organización y economía de las escuelas de esta provincia ${ }^{8}$.

En la Constitución de la República de Colombia promulgada ese mismo año se contemplaron una serie de atribuciones especiales al Congreso para la promoción de la educación pública9 ${ }^{9}$ En respuesta a este mandato, el Congreso de Cúcuta creó una comisión que presentó un proyecto de ley para fundar las escuelas de primeras letras en todos los poblados de la República. El resultado de estas discusiones fue la Ley del 2 de agosto donde quedó explícita la intención de dimensionar "la escuela como el plantel educativo más difundido "[...] pues era el origen sobre el cual se cimentaban los demás conocimientos humanos"10.

$5 \quad$ Roger Pita Pico, “Educación, Patria y Progreso: las escuelas de primeras letras en el Caribe colombiano, 1820-1828”, en El Taller de la Historia Vol. 6: No. 6 (2014), 346.

6 Felipe Osorio Racines, Decretos del General Santander. 1819-1821 (Bogotá: Universidad Nacional, 1969), 154.

7 Alejandro Osorio y Estanislao Vergara, Los encargados de la Secretaría General del Departamento de Cundinamarca presentan a S. E. el General F. de P. Santander, vicepresidente del mismo Departamento, la memoria correspondiente al año de 1820 (Bogotá: Imprenta de Espinosa, 1821), 46.

8 En este reglamento se recomendó el uso de la obra Reglas para enseñar a leer y escribir, el catecismo de Astete y el catecismo de Fleuri de Pouget. Alberto Martínez Boom, Memorias de la escuela pública (Bucaramanga: Universidad Industrial de Santander, 2011), 394-400.

9 Constitución de la República de Colombia (Rosario de Cúcuta: Bruno Espinosa, Impresor del Gobierno General, 1821), 22.

10 Actas del Congreso de Cúcuta 1821 (Bogotá: Biblioteca de la Presidencia de la República, 1990), Vol. II, 157. 
La ley reiteró que los maestros debían enseñar los preceptos cristianos y los valores ciudadanos. El ejercicio militar fue eliminado del horario de clases. El currículo y el método de enseñanza debían ser uniformes en toda la República, para lo cual, había que elaborar cartillas e implementar los reglamentos para la buena gestión administrativa de las escuelas. Asimismo, el Poder Ejecutivo quedó autorizado para que en las principales ciudades se crearan escuelas pilotos con el método lancasteriano ${ }^{11}$, para que de allí se fueran difundiendo a todas las provincias ${ }^{12}$.

En materia de vigilancia, el Decreto del 6 de octubre de 1820, otorgó a los gobernadores políticos la responsabilidad como directores de las escuelas. Ellos mismos debían solucionar las dificultades y efectuar visitas periódicas para evaluar la conducta de los maestros y la buena marcha de esos establecimientos ${ }^{13}$. Entre tanto, el Congreso de Cúcuta creó la figura del director de estudios para cada provincia y descentralizó la labor de inspección con el fin de lograr mejores resultados. Los gobernadores mantenían sus máximas facultades para adelantar visitas y corregir cualquier anomalía o exceso pero a escala local ese rol era asumido por el cabildo y los curas ${ }^{14}$.

\section{La cobertura: anhelos y desilusiones}

En tiempos del dominio hispánico, eran muy reducidas las posibilidades de acceder a la educación, lo cual no hacía más que poner en evidencia las disparidades sociales y étnicas ${ }^{15}$. "Aunque la pretensión del gobierno republicano era cambiar drásticamente este desolador panorama a través de la masiva fundación escuelas en todas las poblaciones, en términos reales esa era una meta difícil de alcanzar, especialmente en estos tiempos de posguerra en que apenas se realizaban ingentes esfuerzos con miras a la recuperación económica"16.

Pocos meses después del triunfo obtenido en la Batalla de Boyacá, se impartieron órdenes directas para establecer escuelas en algunos puntos de la República. El presidente Bolívar mandó en abril de 1820 fundar una escuela en la parroquia de Chitagá, provincia de Pamplona y, para tal efecto, dispuso 40 pesos para el pago del maestro ${ }^{17}$. Mediante un decreto dictado dos meses más tarde, se ordenó abrir una escuela de primeras letras en la Villa del Rosario ${ }^{18}$.

11 José Lancáster era un pedagogo inglés cuyo método de enseñanza, conocido también con el nombre de mutua instrucción, consistía en que un solo maestro pudiera dirigir a un gran número de alumnos debiendo estos colaborarle activamente en esta labor. Véase: Francisco Sanabria Munévar, "Enseñando mutuamente: una aproximación al método lancasteriano y a su aprobación en Colombia", en Revista Historia de la Educación Colombiana Vol. 13: No. 13, (2010), 47-76.

12 Actas del Congreso de Cúcuta, Vol. II, 59, 160.

13 Felipe Osorio Racines, Decretos del General Santander, 154.

14 Actas del Congreso de Cúcuta, Vol. II, 160.

15 Evelyn Ahern, "El desarrollo de la educación", 21.

16 Roger Pita Pico, "Educación, Patria y Progreso", 349.

17 Gaceta de Colombia, No. 40, Villa del Rosario: Imprenta de Espinosa, abril 29 de 1820, 154.

18 Esta población era la cuna del vicepresidente Santander. Luis Antonio Bohórquez Casallas, La evolución educativa en Colombia 
El decreto del 6 de octubre de 1820, dictado por el vicepresidente Santander y la Ley del 2 de agosto de 1821, promulgada por el Congreso de Cúcuta lanzaron algunas fórmulas en el intento por lograr resultados concretos y alcanzables en materia de cobertura. Un tema de hondas implicaciones en este tema era la idea que se había planteado de comprometer a los padres a enviar a sus hijos a la escuela. El Decreto del 6 de octubre de 1820, obligó a los jueces a elaborar un padrón de los niños entre los 4 y 12 años de edad, lo que finalmente obligaría a los padres a enviar a sus hijos a las aulas. Los gobernadores políticos de la provincia tomarían represalias contra aquellos progenitores que se negaran a acatar la anterior orden. Esto no era óbice para que los padres enviaran sus hijos a las escuelas de la capital de provincia o a otra que consideraran más conveniente pero debían reportar esta decisión a los jueces ${ }^{19}$.

En el debate promovido en el Congreso de Cúcuta, el parlamentario José Manuel Restrepo creía que esta imposición coartaba el derecho a la libertad. Una opinión contraria fue esbozada por Antonio María Briceño, quien pensaba que a los padres les asistía el deber de dar a conocer a sus hijos los derechos ciudadanos y para ello era indispensable que estos aprendieran a leer. Así entonces, Briceño era partidario de que las multas quedaran a discreción de los jueces, quienes en últimas debían decidir si existían o no causas justas para penalizar a los padres. Por su parte, el diputado Vicente Azuero creía que debía hacerse una distinción entre los habitantes de los centros urbanos y los que vivían en los campos, pues no siempre estos gozaban de la capacidad económica suficiente para mantener a sus hijos en los poblados. Una razón de peso adicionó el congresista Nicolás Ballén de Guzmán a esta discusión tras considerar que no tenía sentido presionar a los padres, cuando estos apenas tuviesen un hijo como único jornalero de la casa, cuyo trabajo se demostrara que era vital para la subsistencia familiar.

Luego de ser sopesados estos criterios, en el texto final de la "Ley del 2 de agosto de 1821, se resolvió que, siendo una prioridad el que todos los pequeños aprendieran los principios básicos del saber, los jueces debían formar un padrón de los niños de 6 a 12 años de edad, obligando a los padres que no se hubiesen decidido aún a remitir a sus hijos a la escuela en el término de un mes después de cumplida la edad necesaria o de haberse constituido este centro. Los omisos incurrirían en una multa de cuatro pesos que sería duplicada y aplicada para el fondo de la misma escuela si en el plazo adicional de 15 días no atendían el requerimiento. Únicamente serían exceptuados aquellos vecinos en estado de pobreza que viviesen distantes del pueblo. De todos modos, estas medidas de carácter coercitivo no eran impedimento para que los padres brindaran a sus hijos una instrucción privada o para que los ubicaran en el plantel de su preferencia" ${ }^{20}$.

(Bogotá: Publicaciones Cultural Colombiana, 1956), 226.

19 Felipe Osorio Racines, Decretos del General Santander, 154.

20 Actas del Congreso de Cúcuta, Vol. II, 56-59, 159; Roger Pita Pico, "Educación, Patria y Progreso", 353 
Las cifras en cobertura fueron ganando fuerza con el transcurrir de los años. En diciembre de 1821, el gobierno de Antioquia daba cuenta de haber trabajado activamente en la fundación de 50 escuelas, la mayoría con recursos suficientes para el sostenimiento de los profesores ${ }^{21}$. Sin embargo, algunos inconformismos salieron a la luz pública en el periódico El Eco de Antioquia al denunciarse cómo todavía se veían muchos párvulos ociosos en las calles, entretenidos en riñas de pollos, en tirar piedra o en jugar "chumbimbas" 22. A mediados de mayo de 1822 ya se había instalado en Bogotá la primera escuela lancasteriana. Su promotor era fray Sebastián de Mora, quien había sido enviado preso a España por el general español Pablo Morillo. Tras recobrar su libertad, estudió allí el novedoso método y regresó para aplicarlo en su tierra natal ${ }^{23}$.

Haciendo un balance general, el gobierno central reconoció en abril de 1823, que la Ley del 2 de agosto de 1821, se había ejecutado hasta donde las circunstancias lo habían permitido. Así entonces, una multitud de escuelas se habían constituido pero se abrigaba la esperanza de que a nivel local y provincial se trabajara con mayor "constancia y asiduidad". A manera de comparación, se hizo énfasis en el estancamiento que padeció la educación durante los 300 años de régimen colonial, mientras que ahora se mostraban notables avances en esparcir la enseñanza pública "aún en medio de los peligros de la guerra y del estruendo del cañón" ${ }^{24}$.

Sin duda, los departamentos del área andina central, Cundinamarca y Boyacá, que precisamente habían sido los primeros liberados del yugo español, marcaron un liderazgo en la difusión de la educación elemental. Progresivamente, se fue introduciendo el método lancasteriano, principalmente en las ciudades de mayor importancia. En la tabla 1 aparecen detalladas las localidades de Cundinamarca que para agosto de 1823 contaban con escuelas de primeras letras:

21 Correo de la ciudad de Bogotá, No. 125, Bogotá: Imprenta de Nicomedes Lora, diciembre 16 de 1821, 401.

22 El Eco de Antioquia, No. 18, Medellín: Imprenta del Gobierno por Manuel María Viller-Calderón, septiembre 15 de 1822, 76.

23 Gaceta de Colombia, No. 29, mayo 5 de 1822, 2.

24 José Manuel Restrepo, Memoria que el secretario de Estado y del despacho del Interior presentó al Congreso de Colombia sobre los negocios de su Departamento (Bogotá: Imprenta de Espinosa, 1823), 25-26. 
Tabla 1. Escuelas establecidas en el departamento de Cundinamarca, 1823

\begin{tabular}{|c|c|c|}
\hline Provincia & Localidad & Método \\
\hline \multirow{2}{*}{ Bogotá } & $\begin{array}{l}\text { Barrio de la Catedral, parroquia de Las Nieves, Colegio de } \\
\text { Universidad, convento de San Francisco, parroquias de Usaquén, } \\
\text { Zipacón, Serrezuela, Cáqueza, Choachí, Zipaquirá, Ubaté, Nemocón, } \\
\text { Cota, Guaduas, La Vega. }\end{array}$ & Lancasteriano \\
\hline & $\begin{array}{l}\text { Parroquias de Fontibón, Bosa, Bogotá, Bojacá, Engativá, Facatativá, } \\
\text { Fómeque, Ubaque, Chipaque, Fosca, Une, Chocontá, Machetá, } \\
\text { Tibirita, Manta, Gachetá, Chipasaque, Guasca, Guatavita, Cogua, } \\
\text { Gachancipá, Chía, Tabio, Villeta, Quebradanegra, Chaguaní, } \\
\text { Fusagasugá, Melgar, Soacha, Cajicá, Cucunubá, Suesca, Fúquene. }\end{array}$ & Común o antiguo \\
\hline Neiva & $\begin{array}{l}\text { Ciudad de Neiva, parroquias de Guagua, Retiro, Yaguará, } \\
\text { Purificación, Plata, Timaná, Gigante, Garzón, Pital. }\end{array}$ & Común o antiguo \\
\hline Mariquita & $\begin{array}{l}\text { Mariquita, Ibagué, Chaparral, Guamo, Piedras, La Palma, Caparrapí, } \\
\text { Peña, Mesa, Bituima, Anolaima, Rioseco, San Antonio. }\end{array}$ & Común o antiguo \\
\hline \multirow[b]{2}{*}{ Antioquia } & Villa de Medellín, ciudad de Rionegro. & Lancasteriano \\
\hline & $\begin{array}{l}\text { Parroquias de Belén, San Cristóbal, Estrella, Envigado, Amagá, } \\
\text { Titiribí, Hatoviejo, Copacabana, Barbosa, Iguanacita, Santa Fe de } \\
\text { Antioquia, Sopetrán, San Jerónimo, Cañasgordas, Sabanalarga, } \\
\text { Buriticá, Urrao, Sacaojal, Guarne, San Vicente, Lachapa, Concepción, } \\
\text { Santo Domingo, Ceja, Retiro, Pereira, Abejorral, Sonsón, Aguadas, } \\
\text { Sabaletas, Marinilla, Peñol, Carmen, Santuario, Baos, Santa Rosa, } \\
\text { San Pedro, Yarumal, Claras, Donmatías, Zaragoza, Remedios, } \\
\text { Yolombó, Cancán, San Bartolomé. }\end{array}$ & Común o antiguo \\
\hline
\end{tabular}

Fuente: Gaceta de Colombia, No. 94, agosto 3 de 1823, 3.

En la ciudad de Neiva y en las parroquias de Villavieja y Yaguará se implementó el nuevo método lancasteriano a finales de 1824. Ese mismo año se erigió escuela en la población de El Espinal ${ }^{25}$. A febrero de 1824, estas eran las escuelas fundadas en el departamento de Boyacá:

Tabla 2. Escuelas establecidas en el departamento de Boyacá, 1824

\begin{tabular}{|l|l|l|}
\hline Provincia & \multicolumn{1}{c|}{ Localidad } & \multicolumn{1}{c|}{ Método } \\
\hline \multirow{5}{*}{ Tunja } & $\begin{array}{l}\text { Tunja, Villa de Leiva, Ramiriquí, Tibaná, Guachetá, Lenguazaque, } \\
\text { Chiquinquirá, Sátiva Norte, Sátiva Sur, Soatá, Santa Rosa, Cerinza, } \\
\text { Duitama. }\end{array}$ & Lancasteriano \\
\cline { 2 - 3 } & $\begin{array}{l}\text { Samacá, Suta, Ráquira, Tinjacá, Gachantivá, Tenza, Guateque, } \\
\text { Sutatenza, Capilla de Tenza, Pachavita, Macanal, Somondoco, } \\
\text { Guayatá, Miraflores, San Fernando, Garagoa, Sogamoso, Tibasosa, Común } \\
\text { Firavitoba, Pesca, Iza, Gámeza, Socha, Nobsa, Salina de Chita, } \\
\text { Guacamayas, Chiscas, El Espino. }\end{array}$ & . \\
\hline
\end{tabular}

25 Luis Horacio López Domínguez (comp.), Obra educativa de Santander 1819-1826 (Bogotá: Biblioteca de la Presidencia de la República, 1990), Vol. I, 215; Gaceta de Colombia, No. 129, abril 4 de 1824, 1-2. 
Fundar escuelas para consolidar la República y formar ciudadanos.

Una aproximación para el caso colombiano, 1819-1825

\begin{tabular}{|c|c|c|}
\hline Provincia & Localidad & Método \\
\hline \multirow[b]{2}{*}{ Socorro } & Socorro, Vélez. & Lancasteriano \\
\hline & $\begin{array}{l}\text { San Gil, Barichara, Páramo, Confines, Oiba, Guadalupe, Palmar, } \\
\text { Simacota, Charalá, Ocamonte, Sincelada, Encino, Riachuelo, } \\
\text { Puente Nacional, San Benito, Guavatá, La Paz, Cite, Valle de Jesús, } \\
\text { Moniquirá, Tocuy, Chitaraque, Pare, Pinchote, Valle de San José, } \\
\text { Aratoca, Mogotes, Petaquero, Onzaga, Curití, Cabrera, Robada, } \\
\text { Zapatoca. }\end{array}$ & Común \\
\hline \multirow[b]{2}{*}{ Pamplona } & Pamplona. & Lancasteriano \\
\hline & $\begin{array}{l}\text { Girón, Villa del Rosario de Cúcuta, Chopo, Silos, Labateca, Chitagá, } \\
\text { Piedecuesta, Bucaramanga, Matanza, Tona, Cepitá, Málaga, San } \\
\text { Andrés, Guaca, Tequia, Molagavita, Concepción, Cerrito, Servitá, } \\
\text { Enciso, Capitanejo, Macaravita, San Miguel, Carcasí, San José, San } \\
\text { Cayetano, Salazar, Santiago. }\end{array}$ & Común \\
\hline \multirow[b]{2}{*}{ Casanare } & Nunchía, Cravo. & Lancasteriano \\
\hline & $\begin{array}{l}\text { Pore, Santiago, Marcote, Arauca, Trinidad, Támara, Ten, Carrastol, } \\
\text { Surimena, Casimena, Labranzagrande, Paya, Pisba, Betoyes, } \\
\text { Macaguane, Manare, Tame, Taguana, Zapatosa, Chámeza. }\end{array}$ & Común \\
\hline
\end{tabular}

Fuente: Gaceta de Colombia, No. 120, febrero $1^{\circ}$ de 1824, 1.

Escasos eran los adelantos registrados en el departamento del Magdalena. No hay que olvidar que la región Caribe tardó mucho más tiempo en expulsar a los realistas pues Santa Marta solo pudo ser liberada en noviembre de 1820, mientras que Cartagena lo logró en octubre del año siguiente. Para finales de 1823, en la provincia de Cartagena existían en su ciudad capital y en Mompós sendos centros educativos con el método lancasteriano ${ }^{26}$. Con el modelo antiguo, funcionaban escuelas en Barranquilla, Tubará, Chinú y Lorica. Solo una escuela con el método antiguo funcionaba en la provincia de Santa Marta y estaba ubicada en la villa de Ocaña. A pesar de la devastación derivada de la guerra, pronto empezaron a verse algunos progresos. Según la prensa oficial, para mediados de 1824, todos los pueblos de la provincia de Santa Marta ya contaban con escuelas públicas. El 5 de enero de 1825, se abrió un plantel educativo con 80 niños en Turbaco gracias a los esfuerzos "patrióticos" del alcalde Antonio Castañeda ${ }^{27}$.

La región del Sur, particularmente las provincias de Popayán y Pasto, también habían sentido los rigores de la prolongación de la lucha independentista y, desde luego, esto repercutió en la expansión de los planes educativos del naciente régimen republicano. Así entonces, a principios de 1823 se estableció en la ciudad de Popayán una escuela con el método lancasteriano ${ }^{28}$.

Con la culminación de la guerra, se hizo más propicio el ambiente para lograr un mayor cubrimiento. A juzgar por las estadísticas manejadas por el gobierno,

\footnotetext{
26 Gaceta de Cartagena de Colombia, No. 129, Cartagena: Imprenta del Gobierno por Juan Antonio Calvo, enero 31 de 1824, 538.

27 Gaceta de Colombia, No. 115, diciembre 28 de 1823, 1; No. 134, mayo 5 de 1824, 2; No. 175, febrero 20 de 1825, 3.

28 Gaceta de Colombia, No. 71, febrero 23 de 1823, 3.
} 
para el mes de noviembre de 1825 existían escuelas en prácticamente todas las provincias de la República ${ }^{29}$.

Algunas fundaciones de escuelas se realizaron en medio de actos solemnes y en determinados casos coincidieron con fechas de celebraciones patrióticas, con lo cual se pretendía imprimir mayor realce a este tipo de acontecimientos y al mismo tiempo enviar un mensaje de estímulo a otras localidades a fin de que se animaran a crear este tipo de establecimientos. Aquí la intención de fondo era entronizar en la comunidad las virtudes de los principios republicanos asociándolos con el impulso de la cultura y la educación dentro de un nuevo modelo de nación ${ }^{30}$.

El 20 de octubre de 1821, se realizó una fiesta sencilla en Tunja para inaugurar las clases en la escuela pública fundada por la comunidad de franciscanos, celebración a la cual concurrió el presidente Simón Bolívar a su paso por aquella ciudad. Este plantel, inaugurado con 100 alumnos, era uno de los 32 que a la fecha funcionaban en la provincia de Tunja ${ }^{31}$.

El 24 de enero de 1823, abrió sus puertas la escuela lancasteriana de la villa de Medellín en medio de música militar, desfile de los escolares y discurso del gobernador provincial. La dotación estrenada ese día constaba de 18 mesas, 18 bancos, 68 pizarras, 68 lapiceros, 68 lápices, 58 silabarios y 30 escudos para monitores en tanto que otros útiles más fueron encargados a Jamaica ${ }^{32}$. La fundación de la escuela en la parroquia de Ortega en la provincia de Mariquita se llevó a cabo el 7 de agosto de 1825, justo cuando se cumplía el sexto aniversario de la Batalla de Boyacá. En el acto, organizado en honor al vicepresidente Santander, se juntaron 27 jóvenes entre blancos e indígenas, quienes junto a las autoridades locales y el vecindario presenciaron una misa de acción de gracias. Luego regresaron a la escuela y allí el cura pronunció una arenga a los niños en la que se expresaba la importancia de rendir tributo a la República y dar gracias al gobierno por este nuevo servicio educativo:

"[...] haciéndoles ver la felicidad de que iban a gozar, de que habian carecido sus antepasados por la opresión de los tiranos; que esta era la primera escala para llegar al conocimiento y luces de las ciencias; que con este conocimiento serían fieles a las leyes y magistrados, buenos hijos y mejores ciudadanos y hombres libres, útiles a sí, a sus familias y al Estado; que debian grabar en sus corazones la gratitud al gobierno que les había proporcionado por medio de sus órdenes, sacarlos de las tinieblas de la ignorancia [...] y volviéndose a los padres de los niños y demás concurso, les dijo otras cosas al intento, y exhortó a todos para que siempre rogasen a Dios por el gobierno, y que en sus bocas se oyese siempre: joiva el inmortal Bolivar! jviva el protector de las

29 José Manuel Restrepo, Exposición que el Secretario de Estado del Despacho del Interior de la República de Colombia hizo al Congreso de 1826 sobre los negocios de su Departamento (Bogotá: Imprenta Manuel M. Viller-Calderón, 1826), 17.

30 A su paso por Colombia, el viajero James Thomson observó cómo la Constitución de la República de 1821 era utilizada habitualmente en las escuelas como texto para ejercitar la lectura. Evelyn Ahern, "El desarrollo de la educación", 29.

31 Correo de la ciudad de Bogotá, No. 121, noviembre 18 de 1821, 390.

32 El Eco de Antioquia, No. 36, enero 26 de 1823, 148. 
ciencias, Santander! Con lo que se concluyó el acto, manifestando todos el contento, por medio de las vivas y demostraciones de júbilo"33.

Tres meses más tarde fue erigida la escuela de primeras letras de Honda con el método lancasteriano. Además de misa y discursos oficiales, se desarrolló una corrida de toros por la tarde y por la noche un baile para diversión de toda la comunidad $^{34}$.

El espíritu de celebración pública cobijó también las actividades académicas. En el Artículo $11^{\circ}$ del Decreto del 6 de octubre de 1820 se dispuso que cada cuatro meses, bajo la presencia de las autoridades provinciales, el cura, los jueces del lugar y los escolares, organizaran un certamen sobre las materias cursadas para juzgar el nivel de aprendizaje. La Ley del 2 de agosto del año siguiente, dio continuidad a estos concursos académicos con premios a manera de incentivos. Muchos de estos eventos fueron publicados en la prensa oficial con el fin de exaltar la evolución de los educandos y del proyecto educativo en marcha.

El 24 de diciembre de 1822, con ocasión de las fiestas nacionales efectuadas en Bogotá para proclamar las glorias militares de Colombia, el director de la escuela lancasteriana don José María Triana presentó a 16 alumnos destacados para que demostraran públicamente sus habilidades en geografía y aritmética. Hablaron además sobre el catecismo de Fleury y sobre el panorama político de la República $^{35}$. En el marco de las fiestas nacionales llevadas a cabo en esta misma capital el 24 de diciembre del año siguiente, 12 muchachos salieron bien librados en el conocimiento del viejo y nuevo Testamento, la gramática española y el cálculo ${ }^{36}$.

La escuela de Simití, en el departamento del Magdalena, organizó el 10 de septiembre de este año un certamen público en homenaje al vicepresidente Santander. Una enérgica alocución del párroco Luis Serrano abrió la programación. Con tan solo dos meses de iniciadas las clases, un grupo de cinco niños se distinguieron por haber respondido acertadamente el examen de ortografía y gramática, en razón a lo cual recibieron un premio del cabildo al tiempo que se expresaron felicitaciones al maestro.

Una de las tantas iglesias de la ciudad de Tunja fue escenario el 29 de febrero de 1824 de un certamen público en el que se resaltó cómo un grupo de cuatro niños, cuyas edades no sobrepasaban los siete años, describían "con sus manos inocentes" la situación topográfica de Europa y Asia, luego de haber pronunciado sendos discursos exaltando el heroísmo del general Bolívar. De

\footnotetext{
33 Gaceta de Colombia, No. 205, septiembre 18 de 1825, 1.

34 Gaceta de Colombia, No. 215, noviembre 27 de 1825, 1.

35 Gaceta de Colombia, No. 64, enero 5 de 1823, 2.

36 Correo de Bogotá, No. 3, enero 9 de 1824, 11.
} 
estos cuatro "tiernos colombianos", Carmelo Vargas ocupó el primer lugar y por ello fue premiado con una onza de oro ${ }^{37}$.

Otro evento de este tipo se llevó a cabo el 9 de noviembre de 1825 en Garagoa donde "[...] fue un motivo de placer para los vecinos de dicha villa que veían en las ventajas de aquel establecimiento el fundamento de sus más halagüeñas esperanzas, y un justo premio de los sacrificios que han hecho por la Patria" ${ }^{\prime 38}$. En el certamen desarrollado el 27 de diciembre de este año en Honda, los estudiantes ratificaron sus avances en el arte de escribir y en conocer las bases de la Constitución y geografía de Colombia, la historia sagrada y la aritmética. A finales del año siguiente en Bogotá, se destacó en la prensa oficial cómo un niño de cinco años, hijo de un artesano, respondía con viveza varias preguntas sobre los derechos del hombre en presencia de un concurrido auditorio encabezado por el vicepresidente Santander.

\section{Los dilemas de la financiación}

“Las fuentes de financiación de la educación pública fue uno de los temas más álgidos de discusión durante la naciente República. Varias opciones de recursos públicos, privados y mixtos fueron analizadas al interior del gobierno y del Congreso ante el déficit de las arcas públicas, los crecidos gastos destinados a la guerra y el estado de desaceleración económica ${ }^{39}$. Los saqueos, los embargos, los donativos, las contribuciones forzosas y la ruina provocada por la confrontación militar, eran factores que habían generado un impacto generalizado" ${ }^{40}$. En su Decreto del 6 de octubre de 1820, el vicepresidente Santander ordenó que las ciudades y villas con rentas de propios tenían que establecer una escuela pública. Para tal efecto, los gobernadores políticos obligarían a los cabildos para que "inmediatamente y sin excusa" procedieran a realizar esta fundación. Además de esto, era deber de cada convento de religiosos, excepto los de San Juan de Dios, instalar una escuela.

Las parroquias que contaran con los treinta o más vecinos que prescribía la Ley de Indias, debían también fundar escuela pública pero costeada por ellos mismos. El juez político o comandante militar de cada localidad debía concientizarlos de la importancia de este propósito y comprometerlos a sufragar mensualmente una cantidad proporcional a las posibilidades económicas de cada uno, cuya suma total no podía exceder de 300 pesos ni ser inferior a 200. Todos los propietarios estaban obligados al aporte así no vivieran en sus heredades. En

\footnotetext{
37 Gaceta de Colombia, No. 109, noviembre 16 de 1823, 3; Gaceta de Colombia, No. 129, abril 4 de 1824, 1-2.

38 Gaceta de Colombia, No. 171, enero 23 de 1825, 2; Gaceta de Colombia, No. 217, diciembre 11 de 1825, 3.

39 Se sabe por lo menos que en el año fiscal de 1825-1826, aproximadamente las tres cuartas partes de los gastos del Estado estaban enfocados hacia el estamento militar. David Bushnell, El Régimen de Santander en la Gran Colombia (Bogotá: El Áncora, 1985), 122.

40 Roger Pita Pico, "Educación, Patria y Progreso", 357.
} 
los pueblos pequeños con menos de treinta vecinos, los padres podían mandar a sus hijos a las escuelas de las ciudades más próximas ${ }^{41}$.

En el debate dado en el Congreso de Cúcuta de 1821, el diputado Francisco Soto hizo énfasis en el hecho de que en algunas ciudades y villas la renta de propios no alcanzaba para cubrir los gastos de escuelas pero en otras sobraban y podían ser repartidos. El congresista Francisco José de Otero, puso de presente el ejemplo de San Gil donde fue posible no solo dotar la escuela local sino además, girar 30 pesos para cada parroquia de dicho cantón. En estos casos, aseveró Otero, era injusto afectar a los parroquianos imponiéndoles una contribución. Otras voces se alzaron para recordar que los recursos de propios debían cubrir también otras prioridades inaplazables.

Para el legislador Félix de Restrepo, la base mínima vigente de 30 vecinos para establecer escuela era una proporción muy pequeña y propuso que se elevara a más de 100, entendiéndose que aquellos pueblos que no alcanzaran a ese número debían trasladar sus hijos a aquellos núcleos urbanos más grandes. Por su parte, el congresista Miguel Tobar consideraba que la fundación de escuelas no debía hacerse con base en el número de vecinos sino en las riquezas existentes en cada lugar y, para calcular esto, lo mejor era a través de los diezmos debiendo utilizarse una parte de este tributo para el propósito de fomentar la educación pública.

Después de estas reflexiones, la Ley del 2 de agosto de 1821, decidió que en todas las ciudades, villas y parroquias de más de 100 vecinos debía haber por lo menos una escuela de primeras letras. Las ciudades y villas sufragarían los gastos de dotación con los recursos de las rentas de propios pero allí donde estos recursos fueren insuficientes $\mathrm{y}$, en las parroquias, había que recurrir a la solidaridad de los vecinos, comprometiéndose voluntariamente a efectuar los pagos mensuales. Si de este modo no se cubría la cantidad requerida para la escuela, las autoridades locales se encargarían de hacer un repartimiento "justo y moderado" teniendo en cuenta el patrimonio y número de hijos. Esta lista cobijaba a los solteros y exceptuaba a los pobres, cuyos hijos accederían gratuitamente a la educación. Era también deber de los vecinos conseguir la sede para la escuela y los demás útiles indispensables.

La financiación, tal como quedó estipulada en esta ley suscitaba algunas inequidades. Sobre esto ya había alertado en las discusiones previas el congresista Bartolomé Osorio al señalar que los lugares marginados eran los más gravados siendo sus vecinos los más "desdichados" económicamente mientras que las ciudades y villas, que por lo general contaban con mayor prosperidad y recursos, sus habitantes no estaban supeditados a ninguna contribución ${ }^{42}$.

La Ley del 28 de julio de 1821 dispuso que los fondos, bienes y edificios de los conventos suprimidos fueran invertidos en la educación pública. De acuerdo

41 Felipe Osorio Racines, Decretos del General Santander, 154.

42 Actas del Congreso de Cúcuta, Vol. II, 48, 158. 
con esto, el vicepresidente Santander dictó un Decreto el 21 de diciembre de 1822, creando escuela en la ciudad de Mariquita en el convento suprimido de San Francisco y al catedrático, que sería un religioso, se le entregó la iglesia con todas las alhajas. Lo mismo se dispuso en Honda e Ibagué. En Vélez, el convento de San Francisco fue convertido en una casa de educación con una escuela de primeras letras ${ }^{43}$.

En un informe presentado en abril de 1823, el secretario del Interior don José Manuel Restrepo, creía que el gran impase en el plan de establecimiento de escuelas era la penuria económica de los padres de familia de algunos pueblos que carecían de medios para dotar al maestro pero se aferraba a la esperanza de que ese inconveniente sería superado a medida que se sintieran los efectos de la tranquilidad interior después de los rigores de la guerra. Todavía escaseaban los libros para esta primera etapa de enseñanza pero se esperaba que aumentaran las imprentas para así multiplicar las ediciones ${ }^{44}$. Los reportes indicaban que algunos preceptores optaban por abandonar la escuela ante la imposibilidad que existía de poder recaudar sus salarios entre los vecinos. En aras de una mayor estabilidad, al año siguiente el gobierno propuso reformar la ley para procurar que en cada parroquia se estableciera una contribución fija ${ }^{45}$.

En su intervención del 6 de abril de 1824 en la apertura de las sesiones del Congreso, el vicepresidente Santander también reconoció el lento progreso de la educación básica debido a que los pueblos no podían soportar la carga de la contribución para las escuelas teniendo aún la responsabilidad de ayudar para la estabilidad y conservación de la independencia política alcanzada hacía poco. Por ello, instó al máximo ente legislativo para que autorizara destinar algunos gastos del erario nacional a favor de dicho propósito ${ }^{46}$.

Era claro que el Estado no estaba en capacidad de cubrir todas las necesidades a nivel nacional. Por eso, en julio de 1824 se suscitó un álgido debate al interior del Senado en relación con una propuesta que pretendía erigir una escuela en Riohacha con cargo a las rentas públicas en consideración a la situación deficitaria de esta ciudad costera luego de haber padecido un voraz incendio ${ }^{47}$. "Algunos congresistas advirtieron que no se podían fijar preferencias pues muchas otras poblaciones compartían también el anhelo de instalar una escuela con los recursos del erario central. Especialmente, se temía que surgieran quejas y resentimientos en las localidades más pobres o en aquellas que habían dado muestras incuestionables de sacrificio por la patria y la Independencia. Al final, se aprobó la proposición pero con la condición de que esta asignación se aplicara

\footnotetext{
43 Gaceta de Colombia, No. 64, enero 5 de 1823, 2; Gaceta de Colombia, No. 146, $1^{\circ}$ de agosto de 1824, 2.

44 José Manuel Restrepo, Memorias... 1823, 26.

45 José Manuel Restrepo, Exposición que el Secretario de Estado del Despacho del Interior de la República de Colombia hizo al Congreso de 1824 sobre los negocios de su Departamento (Bogotá: Imprenta de la República por Nicomedes Lora, 1824), 9.

46 Luis Horacio López Domínguez (Comp.), A los colombianos: proclamas y discursos, 1812-1840 (Bogotá: Biblioteca de la Presidencia de la República, 1988), 191-193.

47 Roger Pita Pico, “Educación, Patria y Progreso", 359
} 
por el término de cinco años "a menos que antes la renta de propios alcance a cubrir este gasto" ${ }^{48}$. En desarrollo de esta decisión, se ordenó una partida inicial de 300 pesos" $^{\prime \prime}$.

Otro punto en discusión fue el de las prioridades al momento de distribuir las rentas locales. En enero de 1825 el senador Pedro Antonio Hoyos consideró que merecía mayor importancia la composición de caminos que la instrucción pública porque esta no podía difundirse hasta tanto no se arreglaran las vías para facilitar la movilización hasta los establecimientos educativos ${ }^{50}$.

En atención al cúmulo de críticas y reclamos, el 11 de abril de 1825, la ley sobre rentas municipales proveyó algunos auxilios para las escuelas, recursos con los cuales se pretendía subsanar en parte el problema de la falta de maestros y de libros de enseñanza ${ }^{51}$. A fin de cuentas, esto era simplemente un paliativo frente a la dimensión de las necesidades a escala regional.

Ante el desolador panorama de crisis en las arcas oficiales, surgieron algunas alternativas de financiación que fueron de gran ayuda para el fomento de la educación básica, tales como: los estancos, los impuestos y los donativos de carácter privado. Bien es sabido que en tiempos del dominio hispánico, el recaudo tributario se constituyó en una alternativa de financiación en materia de inversión social ${ }^{52}$. En la discusión dada en el Congreso de Cúcuta, el diputado Salvador Camacho propuso que los particulares a quienes se les había concedido el derecho oficial para el cobro del paso y uso de puentes, canoas y cabuyas, contribuyeran para la fundación de escuelas. No obstante, esta propuesta fue rechazada por algunos que consideraban injusto imponer un nuevo peso a quienes tenían ya capitulado con el gobierno el cobro de aquellos derechos ${ }^{53}$. En mayo de 1824 el cabildo de Charalá sugirió crear un impuesto a los cuatro puentes existentes en aquella jurisdicción en beneficio de las exiguas rentas municipales, recursos que serían destinados preferentemente a la educación pública $^{54}$.

Las rentas de productos estancados fueron vistas como otra opción más de subvención ${ }^{55}$. El gobernador político del Socorro recordó que en aquella

48 Santander y el Congreso de 1824. Actas y correspondencia. Senado (Bogotá: Biblioteca de la Presidencia de la República, 1989), Vol. III, 219-243.

49 Acuerdos del Consejo de Gobierno de la República de Colombia, 1821-1824 (Bogotá: Biblioteca de la Presidencia de la República, 1988), Vol. I, 256; Roger Pita Pico, "Educación, Patria y Progreso", 359-360.

50 Santander y el Congreso de 1825. Actas y correspondencia. Senado (Bogotá: Biblioteca de la Presidencia de la República, 1989), Vol. I, 61.

51 Codificación Nacional de todas las leyes de Colombia desde el año de 1821 (Bogotá: Imprenta Nacional, 1924), Vol. II, 17-35.

52 El misionero Joaquín de Finestrad propuso a finales del siglo XVIII gravar los juegos y chicherías con el fin de captar recursos para la fundación de escuelas públicas. Joaquín de Finestrad, El Vasallo Instruido en el estado del Nuevo Reino de Granada y en sus respectivas obligaciones (Bogotá: Universidad Nacional de Colombia, 2000), 157.

53 Actas del Congreso de Cúcuta, Vol. II, 99.

54 Roberto Cortázar, Cartas y mensajes de Santander (Bogotá: Editorial Voluntad, 1954), IV, 391.

55 En tiempos de la Primera República Federativa, en diciembre de 1813, los gobernantes de Zipaquirá propusieron que la casa que antes servía de sede para la Administración de Aguardiente fuera el nuevo local para la escuela pues la edificación existente para este propósito educativo era un "pajar" con muchas incomodidades. Archivo General de la Nación (AGN), Sección Archivo Anexo, Fondo Instrucción Pública, tomo 4, f. 533r. 
provincia, en la época anterior a la instauración de la República, a los maestros se les remuneraba de la cantidad que satisfacían los vendedores de aguardiente de caña tomando en administración el ramo y que podría pensarse en retomar esta alternativa para la fundación de escuelas en los pueblos más necesitados ${ }^{56}$.

El vicepresidente Santander propuso restablecer el estanco de aguardiente para con su producto fomentar la escuela pública. El 28 de diciembre de 1820, un grupo de feligreses de la población de Chitagá en la provincia de Pamplona exigió la suspensión del remate de la renta de aguardiente quedando los destiladores postulantes con la obligación de satisfacer la cantidad asignada al maestro de la escuela, realizando para ello los respectivos pagos mensuales. Esta petición se hizo con el fin de que estos vecinos no perdieran la franquicia concedida ${ }^{57}$.

Una alternativa altamente estimada por el gobierno fueron las donaciones. En 1822 el intendente de Cundinamarca donó buena parte de los utensilios para la escuela de primeras letras en la ciudad de Tunja. En la villa de Santa Rosa, intendencia de Boyacá, la escuela pública se mantenía con los derechos de almotacén pero a finales de 1822 fueron suprimidos estos derechos, motivo por el cual cesó la enseñanza en aquel lugar. Informado el gobierno departamental de esta "cruel calamidad", se impartieron instrucciones al juez político y al cura José Ignacio Holguín para que restablecieran allí el servicio educativo. Este religioso fue el primer en dar ejemplo de generosidad al entregar anualmente 50 pesos de las obvenciones de su curato ${ }^{58}$.

Cabe precisar que el vicepresidente Santander ya había hecho un llamado a los curas para que colaboraran con sus rentas al establecimiento de escuelas. En una carta enviada en octubre de 1821, desde la villa del Rosario, el obispo Rafael Lasso de La Vega solicitó que los bienes testamentarios del canónigo Juan Ignacio Gutiérrez fueran aplicados para beneficio de las aulas en los pueblos de la provincia de Pamplona donde este finado religioso había desarrollado su labor pastoral. El presidente Simón Bolívar respaldó esta petición y por ello pidió "[...] no interrumpir las piadosas instituciones testamentarias a favor de la instrucción pública" ${ }^{59}$.

A mediados de 1823, el presbítero Juan Antonio Eguiguren se comprometió a aportar 100 pesos para la dotación de la escuela de primeras letras de Puente Nacional, en la provincia del Socorro, donde era cura. Se colocó a Eguiguren como ejemplo a los párrocos de Colombia con la esperanza de que la multiplicación de este tipo de gestos generosos pronto se viera reflejada en el progreso de la educación elemental ${ }^{60}$.

\footnotetext{
56 Actas del Congreso de Cúcuta, Vol. II, 26.

57 Acotaciones Bolivarianas. Decretos marginales del Libertador (1813-1830) (Caracas: Fundación John Boulton, 1960), 114.

58 Gaceta de Colombia, No. 58, noviembre 24 de 1822, 3; Gaceta de Colombia, No. 57, noviembre 17 de 1822, 1-2.

59 Acotaciones Bolivarianas, 247-248. El mencionado obispo ya había mostrado compromiso con la causa educativa pues en 1800, cuando cumplía su labor pastoral como cura del pueblo de Funza, donó dos casas de paja y bahareque avaluadas en 125 pesos para pagar el maestro de la escuela pública local. AGN, Sección Colonia, Fondo Colegios, tomo 3, ff. 804r-813v. 
Los aportes mancomunados del vecindario significaron también un gran aliento para los esfuerzos en materia educativa. Una junta de vecinos fue convocada en 1822 en Medellín, para componer la sede del colegio donde además estaba situada la escuela lancasteriana. Un total de 122 ciudadanos entregaron aportes que oscilaban entre 1 Real y 200 pesos para un gran recaudo de 1.423 pesos, resaltándose de manera especial el "patriotismo" de José María Uribe por haber sido el mayor donante pese a que ni siquiera tenía hijos ${ }^{61}$. Hacia 1825, los habitantes del Socorro y de las parroquias de su cantón cedieron a favor de la educación pública la cantidad de 3.900 pesos que les adeudaba la República por el empréstito que en 1821 decretó el Congreso Constituyente. Pocos meses atrás la educación pública del contiguo cantón de San Gil se había favorecido también de una donación, esta vez de 16.000 reses que los vecinos cedieron de lo que el Estado republicano les adeudaba por préstamos tramitados durante la época de la revolución ${ }^{62}$.

También se pensó en la viabilidad de ceder el manejo económico de la educación básica a sociedades de carácter privado. El congresista Domingo Briceño creía en 1821 que, siendo la educación uno de los pilares para el impulso de la naciente República, podía confiársele el patrocinio a la Sociedad de Amigos del Pais ${ }^{63}$ que debía establecerse en las cabezas de provincia. Esta sociedad se encargaría de gestionar recursos para la fundación de escuelas ${ }^{64}$. A finales de 1825, el gobierno central expresó su beneplácito por la creación de la Sociedad de Amigos de la instrucción elemental en la ciudad de Mompós con el objeto de difundir el método lancasteriano. Se elevó una invitación a las demás ciudades para que imitaran esta iniciativa en beneficio de la educación, entendida como la "base del sistema político y fuente de la felicidad común"65.

\section{CONCLUSIÓN}

En los primeros años de Colombia como nación independiente, los dirigentes republicanos concibieron la educación como un factor de cohesión y unidad política en torno a instituciones recientemente constituidas con base en los principios liberales ${ }^{66}$. No obstante, este era en realidad un período de transición en el que todavía era evidente la pugna entre dos mentalidades. Una tradicional,

\footnotetext{
61 El Eco de Antioquia, No. 21, octubre 6 de 1822, 88.

62 Gaceta de Colombia, No. 218, diciembre 18 de 1825, 2; Gaceta de Colombia, No. 199, agosto 7 de $1825,1$.

63 Las sociedades patrióticas o también conocidas como sociedades de amigos del país, eran instituciones similares a las existentes en Francia, Inglaterra y España, cuyo propósito era promover los adelantos en la agricultura y el comercio. Margarita Garrido, Reclamos y Representaciones: variaciones sobre la politica en el Nuevo Reino de Granada, 1770-1815 (Santa Fe de Bogotá: Banco de la República, 1993), 67.

64 Actas del Congreso de Cúcuta, II, 48.

65 Gaceta de Colombia, No. 220, enero $1^{\circ}$ de 1826, 3.

66 Jesús Alberto Echeverri Sánchez, Proceso de constitución de la instrucción pública 1819-1835 (Medellín: Universidad de Antioquia, 1984), 27-28.
} 
consolidada a través del período colonial, en la cual se inculcaban unos valores apegados a la moral cristiana en medio de una estructura social altamente jerarquizada. Estos sectores conservadores se mantenían renuentes al cambio y, aunque eran partidarios de extender los beneficios de la educación básica, seguían aferrados a los viejos esquemas de enseñanza.

La otra mentalidad, aún en ciernes, pregonaba la igualdad y la libertad como principios rectores y pretendía conferir mayor importancia a los métodos racionalistas y modernizantes. Así entonces, las tesis y proyectos en torno a la educación primaria se batieron entre lo religioso y lo profano, entre lo privado y lo público, entre la inclusión y la exclusión. En este complejo y continuo debate de fuerzas, fue de gran relevancia el impulso renovador y progresista jalonado por el presidente Simón Bolívar y el vicepresidente Santander.

El Estado republicano dejó ver desde muy temprano su disposición de establecer una participación y una vigilancia más directa en el nivel de educación básica que desde tiempo atrás había recibido gran influencia de la Iglesia. A pesar de esto, los curas mantuvieron su papel de liderazgo en el proceso de formación de escuelas.

Los ambiciosos planes en cobertura de educación primaria se tropezaron con un ambiente hostil signado por la crisis económica, el déficit fiscal y la tensión político-militar en medio de una frágil y fluctuante estructura administrativa. Esta situación conllevó a plantear nuevas y variadas fórmulas de financiación, lo cual implicó un apoyo y un compromiso más activo por parte de la comunidad y de las instancias de gobierno a escala local.

En 1826 se aprobó el Plan de Estudios mediante el cual se dictaron algunas pautas sobre la estructura administrativa de las escuelas, el tipo de instrucción y el pago a maestros. En los años siguientes continuó vigente el problema de la insuficiencia de recursos a lo cual había que sumar un contexto de gran inestabilidad política debido a la disolución del Congreso de Ocaña, la guerra con el Perú, la desintegración de la Gran Colombia y las continuas disensiones entre los generales Bolívar y Santander, y el exilio de este último dirigente.

\section{FUENTES}

Acotaciones Bolivarianas. Decretos marginales del Libertador (1813-1830). Caracas: Fundación John Boulton, 1960.

Actas del Congreso de Cúcuta 1821. Bogotá: Biblioteca de la Presidencia de la República, 1990, Vol. II.

Acuerdos del Consejo de Gobierno de la República de Colombia, 1821-1824. Bogotá: Biblioteca de la Presidencia de la República, 1988, Vol. I. 
Archivo General de la Nación (AGN), Bogotá-Colombia. Fondos: Colegios, Instrucción Pública.

Codificación Nacional de todas las leyes de Colombia desde el año de 1821. Bogotá: Imprenta Nacional, 1924, Vol. II.

Constitución de la República de Colombia. Rosario de Cúcuta: Bruno Espinosa, Impresor del Gobierno General, 1821.

Cortázar, Roberto. Cartas y mensajes de Santander. Bogotá: Editorial Voluntad, 1954, Vol. IV.

Correo de la ciudad de Bogotá. Bogotá: Imprenta de Nicomedes Lora, 1821-1824.

El Eco de Antioquia. Medellín: Imprenta del Gobierno por Manuel María Viller-Calderón, 1822-1823.

Gaceta de Cartagena de Colombia. Cartagena: Imprenta del Gobierno por Juan Antonio Calvo, 1824.

Gaceta de Colombia. Villa del Rosario: Imprenta de Espinosa, 1820-1826

López Domínguez, Luis Horacio (Comp.). A los colombianos: proclamas y discursos, 18121840. Bogotá: Biblioteca de la Presidencia de la República, 1988.

López Domínguez, Luis Horacio (comp.). Obra educativa de Santander 1819-1826. Bogotá: Biblioteca de la Presidencia de la República, 1990, Vol. I.

Osorio Racines, Felipe. Decretos del General Santander. 1819-1821. Bogotá: Universidad Nacional, 1969.

Osorio, Alejandro y Estanislao Vergara. Los encargados de la Secretaría General del Departamento de Cundinamarca presentan a S. E. el General F. de P. Santander, vicepresidente del mismo Departamento, la memoria correspondiente al año de 1820. Bogotá: Imprenta de Espinosa, 1821.

Restrepo, José Manuel. Exposición que el Secretario de Estado del Despacho del Interior de la República de Colombia hizo al Congreso de 1826 sobre los negocios de su Departamento. Bogotá: Imprenta Manuel M. Viller-Calderón, 1826.

Restrepo, José Manuel. Exposición que el Secretario de Estado del Despacho del Interior de la República de Colombia hizo al Congreso de 1824 sobre los negocios de su Departamento. Bogotá: Imprenta de la República por Nicomedes Lora, 1824.

Restrepo, José Manuel. Memoria que el secretario de Estado y del despacho del Interior presentó al Congreso de Colombia sobre los negocios de su Departamento. Bogotá: Imprenta de Espinosa, 1823.

Santander y el Congreso de 1824. Actas y correspondencia. Senado. Bogotá: Biblioteca de la Presidencia de la República, 1989, Vol. III.

Santander y el Congreso de 1825. Actas y correspondencia. Senado. Bogotá: Biblioteca de la Presidencia de la República, 1989, Vol. I. 


\section{REFERENCIAS}

Ahern, Evelyn. "El desarrollo de la educación en Colombia: 1820-1850". Revista Colombiana de Educación No. 22-23 (1991): 5-88.

Bohórquez Casallas. Luis Antonio. La evolución educativa en Colombia. Bogotá: Publicaciones Cultural Colombiana, 1956.

Bushnell, David. El Régimen de Santander en la Gran Colombia. Bogotá: El Áncora, 1985.

Echeverri Sánchez, Jesús Alberto. Proceso de constitución de la instrucción pública 18191835. Medellín: Universidad de Antioquia, 1984.

Finestrad, Joaquín de. El Vasallo Instruido en el estado del Nuevo Reino de Granada y en sus respectivas obligaciones. Bogotá: Universidad Nacional de Colombia, 2000.

García Sánchez, Bárbara Yadira. "La educación colombiana en la Nueva Granada: entre lo doméstico y lo público". Revista Historia de la Educación Latinoamericana No. 7 (2005): 217-238.

Garrido, Margarita. Reclamos y Representaciones: variaciones sobre la política en el Nuevo Reino de Granada, 1770-1815. Santa Fe de Bogotá: Banco de la República, 1993. Martínez Boom, Alberto. Memorias de la escuela pública. Bucaramanga: Universidad Industrial de Santander, 2011.

Pita Pico, Roger. "Educación, Patria y Progreso: las escuelas de primeras letras en el Caribe colombiano, 1820-1828". El Taller de la Historia Vol. 6: No. 6 (2014): 343-376.

Pita Pico, Roger. “Las escuelas coloniales durante la visita de Moreno y Escandón al nororiente neogranadino: el camino hacia la secularización y el equipamiento urbano". Revista Historia de la Educación Colombiana. No. 14 (2011), 31-49.

Sanabria Munévar, Francisco. “Enseñando mutuamente: una aproximación al método lancasteriano y a su aprobación en Colombia". Revista Historia de la Educación Colombiana Vol. 13: No. 13, (2010), 47-76.

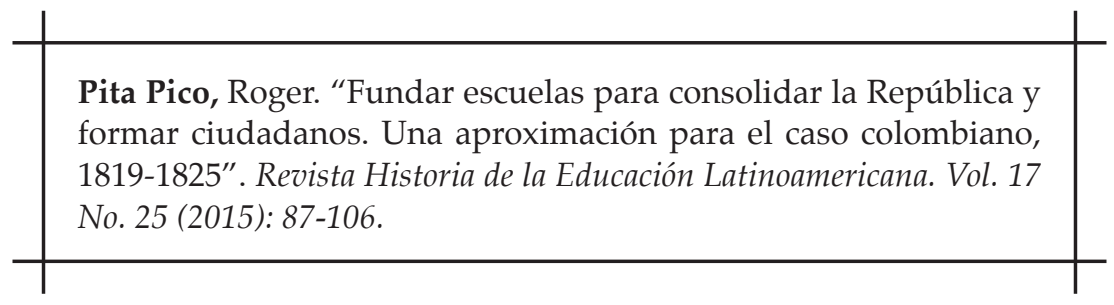

